University of Nebraska - Lincoln

DigitalCommons@University of Nebraska - Lincoln

2013

\title{
The Malthusian-Darwinian dynamic and the trajectory of civilization
}

Jeffrey C. Nekola

University of New Mexico - Main Campus, jnekola@unm.edu

Craig D. Allen

U.S. Geological Survey, craig_allen@usgs.gov

James H. Brown

Santa Fe Institute

Joseph R. Burger

University of New Mexico - Main Campus

Ana D. Davidson

Stony Brook University

See next page for additional authors

Follow this and additional works at: https://digitalcommons.unl.edu/usgsstaffpub

Part of the Geology Commons, Oceanography and Atmospheric Sciences and Meteorology Commons, Other Earth Sciences Commons, and the Other Environmental Sciences Commons

Nekola, Jeffrey C.; Allen, Craig D.; Brown, James H.; Burger, Joseph R.; Davidson, Ana D.; Fristoe, Trevor S.; Hamilton, Marcus J.; Hammond, Sean T.; Kodric-Brown, Astrid; Mercado-Silva, Norman; and Okie, Jordan G., "The Malthusian-Darwinian dynamic and the trajectory of civilization" (2013). USGS Staff -- Published Research. 714.

https://digitalcommons.unl.edu/usgsstaffpub/714

This Article is brought to you for free and open access by the US Geological Survey at DigitalCommons@University of Nebraska - Lincoln. It has been accepted for inclusion in USGS Staff -- Published Research by an authorized administrator of DigitalCommons@University of Nebraska - Lincoln. 


\section{Authors}

Jeffrey C. Nekola, Craig D. Allen, James H. Brown, Joseph R. Burger, Ana D. Davidson, Trevor S. Fristoe, Marcus J. Hamilton, Sean T. Hammond, Astrid Kodric-Brown, Norman Mercado-Silva, and Jordan G. Okie 


\title{
The Malthusian-Darwinian dynamic and the trajectory of civilization
}

\author{
Jeffrey C. Nekola ${ }^{1}$, Craig D. Allen ${ }^{2}$, James H. Brown ${ }^{1,3}$, Joseph R. Burger ${ }^{1}$, \\ Ana D. Davidson ${ }^{1,4}$, Trevor S. Fristoe ${ }^{1}$, Marcus J. Hamilton ${ }^{1,3,5}$, Sean T. Hammond ${ }^{1}$, \\ Astrid Kodric-Brown ${ }^{1}$, Norman Mercado-Silva ${ }^{1,6}$, and Jordan G. Okie ${ }^{1,7}$
}

\author{
${ }^{1}$ Department of Biology, University of New Mexico, Albuquerque, NM, USA \\ ${ }^{2}$ US Geological Survey, Fort Collins Science Center, Jemez Mountains Field Station, Los Alamos, NM, USA \\ ${ }^{3}$ Santa Fe Institute, Santa Fe, NM, USA \\ ${ }^{4}$ Department of Ecology and Evolution, Stony Brook University, Stony Brook, NY, USA \\ ${ }^{5}$ Department of Anthropology, University of New Mexico, Albuquerque, NM, USA \\ ${ }^{6}$ School of Natural Resources and the Environment, University of Arizona, Tucson, AZ, USA \\ ${ }^{7}$ School of Earth and Space Exploration, Arizona State University, Tempe, AZ, USA
}

Two interacting forces influence all populations: the Malthusian dynamic of exponential growth until resource limits are reached, and the Darwinian dynamic of innovation and adaptation to circumvent these limits through biological and/or cultural evolution. The specific manifestations of these forces in modern human society provide an important context for determining how humans can establish a sustainable relationship with the finite Earth.

\section{Malthus, Darwin, and population dynamics}

In 1798 Thomas Malthus laid out the concept of exponential population growth that became the foundation of demography and population biology. He noted that the increase of population is necessarily limited by the means of subsistence.' Population growth can thus continue only as long as environmental conditions remain favorable. As numbers increase, sooner or later environmental limits cause birth rates to decrease and/or death rates to increase, ultimately leading to an end to population growth. These concepts profoundly influenced Charles Darwin half a century later: because more offspring are born than can survive, only the fittest individuals reproduce and pass their superior traits on to their offspring. The result is adaption or innovation in the form of either genetic or cultural evolution.

The Malthusian dynamic pushes a population to increase until it reaches its environmental limits. The Darwinian dynamic pushes against these limits by incorporating new traits and technologies that enhance survival and reproduction. There are restrictions to this Malthusian-Darwinian Dynamic (MDD), however: it is logically, physically, and biologically impossible for exponential growth to continue indefinitely within a finite world.

\section{Ecological and historical perspective on the rise of human civilization}

Humans are an exceptional species. Our population has increased almost continuously from less than a million

Corresponding author: Nekola, J.C. (jnekola@unm.edu)

Keywords: resource limitation; behavioral constraints; sustainability science; macroecology; evolutionary biology. individuals in sub-Saharan Africa 50000 years ago to a current population of 7 billion spanning the entire globe. The human population is projected to reach between 9 and 10 billion by 2050 [1]. In the process, humans have created complex social, technological, and economic systems. We have transformed the atmosphere, water, land, and biodiversity of the planet. We have become the most dominant single species the earth has ever seen. Our success to date is a consequence of our ability to continually develop new innovations that push back environmental limits and to transfer this information across generations (Figure 1). Operating in this way, the MDD has led to rapid cultural evolution and made possible the transition from hunter-gatherer to agricultural to industrialtechnological-informational economies.

A central feature of human ecology has been the positive feedback between growth and innovation. As populations grew and aggregated into larger and more complex social groups, more information was acquired and processed. This led to new technologies that further pushed back ecological limits, allowing for continued population growth. The result has been an ascending spiral of exponential processes feeding back on each other: population growth and aggregation begot technological innovation, which in turn allowed for more resource extraction and a greater ability to overcome ecological constraints, begetting still more population growth and socioeconomic development [2].

Our ability to evade local resource shortages and population crashes through trade, migration, and innovation has allowed for continued growth not just of the global population but also of its resource use and economic activity [3]. For more than 200 years, so-called Malthusians [4] have argued, however, that this cannot indefinitely continue because essential resources supplied by the finite Earth will ultimately become limiting. This Malthusian perspective has historically been countered by so-called Cornucopians, who have argued that there is no hard limit to human population size and economic activity because human ingenuity and technological innovation provide an effectively infinite capacity to increase resource supply [5]. 


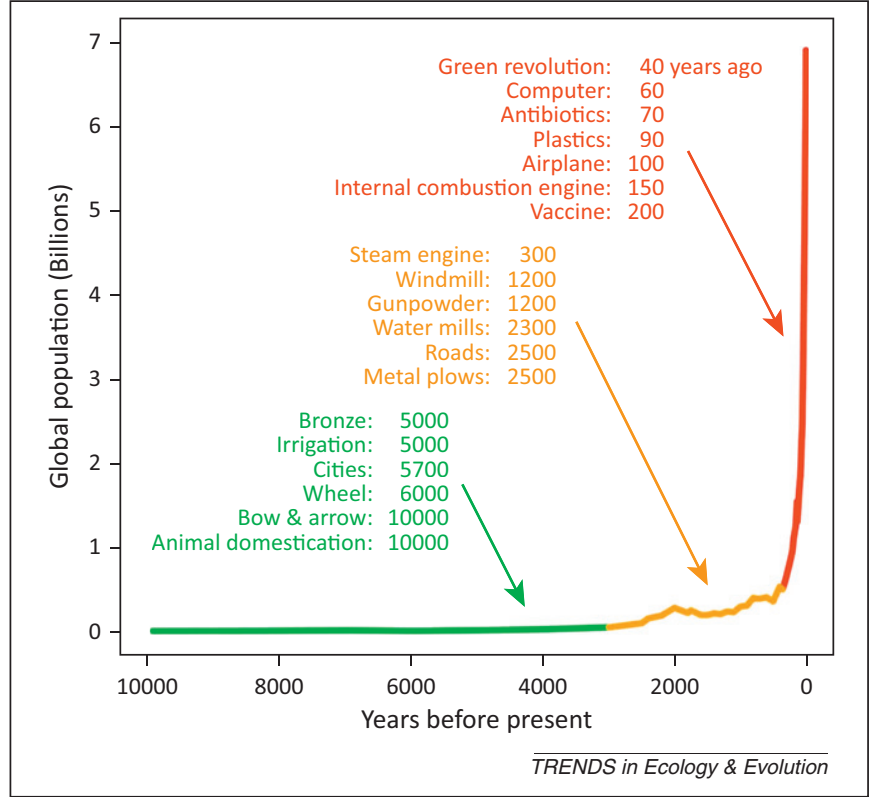

Figure 1. Global human population over the last 10000 years. Data are based on estimates from [11], the US census bureau, and http://en.wikipedia.org/wiki/ World population estimates. Average estimates of population size across these sources are plotted. Examples of major innovations that have helped to expand human carrying capacity (based in part on [12]) are listed for three time periods in years before present (ybp): $10000-3000$ ybp (green), 3000-300 ybp (orange), and 300 ybp-present (red)

Malthus warned of population and economic collapse in the British Isles because the exponentially increasing population would eventually outstrip linearly increasing food supplies. Although millions did die from widespread famines in Ireland and the Scottish Highlands in the mid-19th century, more widespread starvation was averted because of newly acquired agricultural technologies and emigration of people to overseas colonies [2]. As a result, the British economy did not collapse and by 1900 had become the dominant global empire. In the 1960s and 1970s Malthusians again warned that the global human population was nearing its environmental limits. Outbreaks of famine and disease did occur, but advances in agriculture, medicine, technology, and commerce - most notably the green revolution and economic globalization - pushed back the limits again and our population has more than doubled from approximately three billion in 1960 to more than seven billion today [1].

Our ability to evade previous environmental limits through the MDD should not imply, however, that such outcomes are inevitable. First, although the MDD has served as the engine for our extraordinary success, it also contains within it the potential seeds for our ultimate downfall. Motives driven by the MDD, such as selfishness and cheating, benefit individuals at the expense of society as a whole (Box 1). Second, because natural selection can only operate on current conditions, there is little tendency to recognize approaching environmental limits and curb growth before resources are overexploited [6]. Third, the assertion that adaptation and innovation will always prevent collapse - because they have in the past - is logically untenable and akin to the statistical fallacy of

\section{Box 1. The MDD and challenges to global sustainability}

Although the MDD has spurred innovations and adaptations that have allowed us to colonize the entire planet, it has also shaped our biological makeup, selecting for traits and behaviors that favor selfishness and may ultimately make us ill-equipped to act in concert to address global issues.

Natural selection generates the tendency for individuals to preferentially promote themselves and their families. Social groups often establish acceptable behaviors to minimize the inherent conflict between such individual self-interest and group welfare. Although disobeying group rules can result in increased individual fitness, this is counteracted by the detection and punishment of cheaters by social groups. Whether through luck or drive, some will still manage to possess a disproportionate share of resources. Although the degree of inequality can be moderated, highly asymmetric wealth distributions have proven robust to the best efforts of social philosophies and political movements to impose more egalitarian patterns [13].

All of these factors contribute to the tragedy of the commons, which occurs when selfish individuals reap the benefits from shared resources while spreading the costs across the group [14]. The increase in global atmospheric $\mathrm{CO}_{2}$ concentrations and the reduction in global fisheries stocks (Figure 2) both represent pressing global environmental issues related to this mechanism. In the case of $\mathrm{CO}_{2}$ emissions, individuals benefit from using carbon-based energy while global society is burdened by the costs related to increased atmospheric $\mathrm{CO}_{2}$ concentrations. Similarly, a single fishing vessel has no incentive to curb harvests because the costs of reduced stocks are paid for by humanity as a whole. Efforts to implement and enforce international regulations to moderate these two activities have failed because of the selfishness of countries and individuals in combination with the difficulty of detecting cheating at the global scale [15].

extrapolating beyond a data set. Whether we wish to acknowledge it or not, there are hard limits to innovation: according to the first law of thermodynamics, we cannot create energy or matter; according to the second law of thermodynamics, large energy inputs are required to maintain highly organized systems.

The ruins of Mohenjo Daro, Mesopotamia, Egypt, Greece, Rome, the Maya, Hohokam, Angkor Wat, and Easter Island are enduring evidence that many earlier societies were unable to innovate their way out of local limits and therefore collapsed despite attaining dense populations and advanced cultures. Although the proximate causes of these declines are debated and undoubtedly differ, the ultimate causes lie in an inability to sustain resource supplies and protect against parasites, diseases, and other human groups [7].

Until now, both Malthusians and Cornucopians have been correct: some populations have crashed and cultures have vanished, but our species has endured because these events have been localized. However, behavioral changes and technological innovations over the last century now intricately interconnect us in a single global society. As a result, local perturbations currently have the ability to reverberate across all of humanity. For instance, the 2008 meltdown of the USA real estate and mortgage markets and the 2011 Tōhoku earthquake and tsunami in Japan both led to global interruptions in economic activity, impacting most individuals in some way.

Within the context of our now highly globalized society, the essential question is how much potential exists for the 


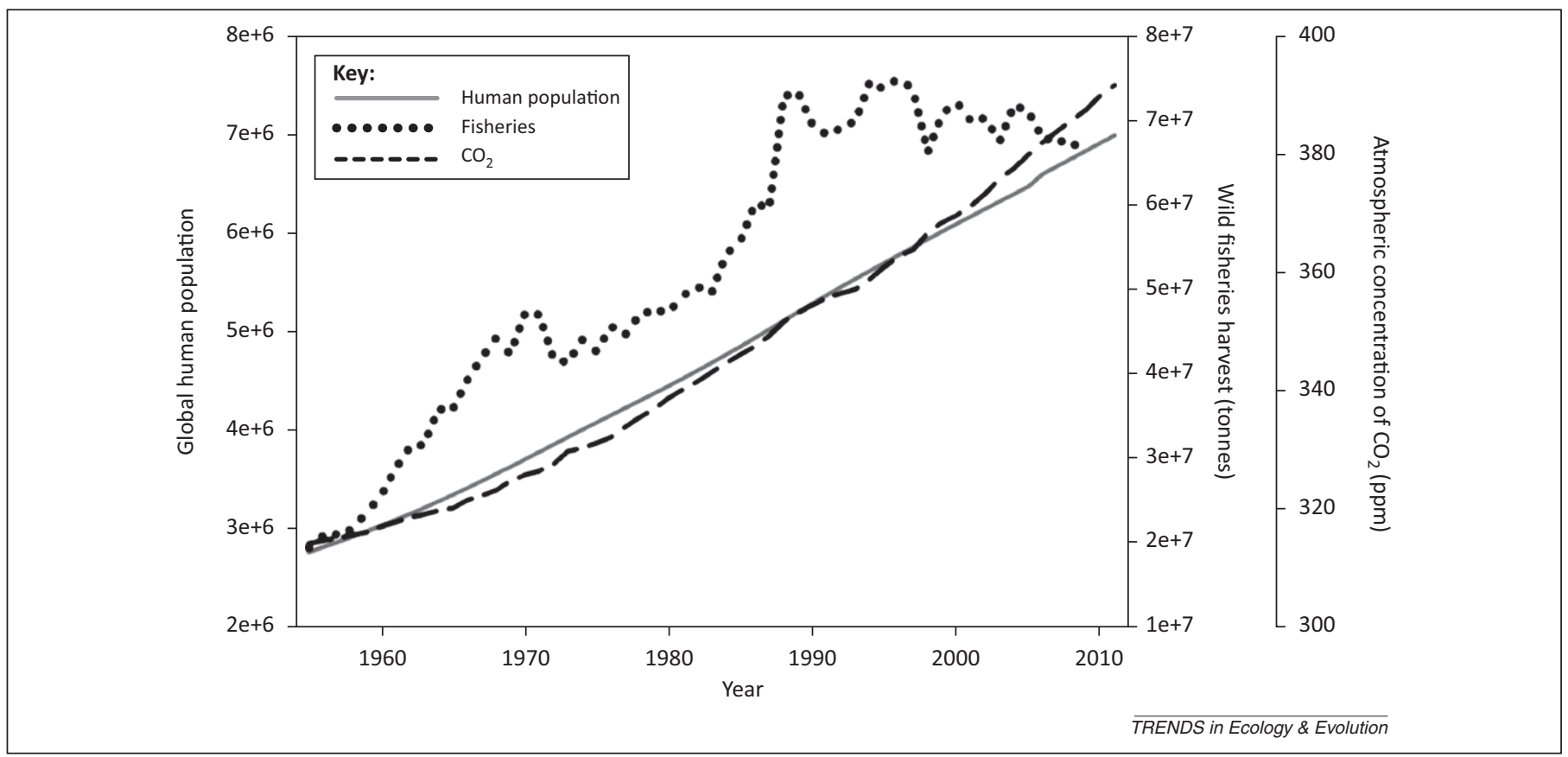

Figure 2. The trajectories of atmospheric $\mathrm{CO}_{2}$ and wild fisheries harvest in relation to global population since 1955 . Note that the increase in $\mathrm{CO}_{2}$ concentration has accelerated, whereas fisheries harvest reached a peak in the 1990s and has since declined. The world population size is from the World Resources Institute (http:// earthtrends.wri.org). The wild fisheries harvest data are from the FAO Fishery Statistical Collection Global Capture Production Database (http://www.fao.org/fishery/ statistics/global-capture-production/en) and are limited to diadromous and marine species. Yearly mean $\mathrm{CO}_{2}$ concentrations as measured at the Mauna Loa Observatory were obtained from ftp://ftp.cmdl.noaa.gov/ccg/co2/trends/co2_annmean_mlo.txt.

Darwinian side of the MDD to allow for continued adaptation and innovation to push back against global scale constraints. Many are now asking questions such as 'What are the limits to growth?' and 'What will happen when these limits are met?' $[5,8]$.

\section{The road forward}

We cannot provide definitive answers to these questions. Contemporary human civilization is a complex adaptive system, maintained far from thermodynamic equilibrium largely via the throughput of vast quantities of increasingly exhausted fossil fuel stocks [9]. This system also requires other essential and non-substitutable commodities such as metal ores, radionucleotides, rare earth elements, phosphate fertilizer, arable land, and fresh water that are becoming ever more scarce [10]. The dynamics of such systems are highly unpredictable. Small perturbations can cause wholesale changes, including total collapse.

The bad news is that the MDD has left humans ill prepared to make the necessary ecological and behavioral changes required to avoid civilization collapse. The universal underlying biological imperatives of the MDD lie at the root of many of the most challenging impediments to longterm sustainability: exponential population growth, exploitation of all available resources, and the expression of behaviors that promote the competitive abilities of individuals, their families, and social groups over the species as a whole.

However, the good news is that the MDD may also provide valuable insights into potential solutions from both natural (in particular evolutionary biology and ecology) and social (in particular economics and sociology) science perspectives. We must recognize that a sustainable future will ultimately require: (i) negative population growth for a number of generations, followed by zero growth; (ii) a steady-state economy based on sustainable use of renewable energy and material resources; and (iii) new social norms that favor the welfare of the entire global population over that of specific individuals and groups. It is also essential that we recognize that humanity has not yet evolved the genetic or cultural adaptations needed to accomplish these tasks.

Our exceptional brains give us the ability to appreciate the present situation and envision alternate futures before catastrophe occurs. The challenge will be to facilitate a rapid cultural evolution that, for the good of the entire species, rewards individual sacrifices in fitness and quality of life. Genuine collaboration between natural and social scientists will be essential to inform society as a whole and policy makers specifically - of this difficult but necessary adaptation required to accommodate our species in a finite and now full world.

\section{References}

1 Bongaarts, J. (2009) Human population growth and the demographic transition. Philos. Trans. R. Soc. B: Biol. Sci. 364, 2985-2990

2 Boserup, E. (1981) Population and Technological Change, University of Chicago Press

3 Hall, C.A.S. and Klitgaard, K.A. (2011) Energy and the Wealth of Nations: Understanding the Biophysical Economy, Springer

4 Ehrlich, P.R. (1968) The Population Bomb, Sierra Club/Ballantine Books

5 Simon, J.L. (1981) The Ultimate Resource, Princeton University Press

6 Levin, S.A. (2000) Fragile Dominion: Complexity and the Commons, Perseus Publishing

7 Tainter, J.A. (1988) The Collapse of Complex Societies, Cambridge University Press

8 Heinberg, R. (2011) The End of Growth: Adapting to Our New Economic Reality, New Society Publishers 
9 Smil, V. (2008) Energy in Nature and Society: General Energetics of Complex Systems, MIT Press

10 Burger, J.R. et al. (2012) The macroecology of sustainability. PLoS Biol. $10, \mathrm{e} 1001345$

11 Durand, J.D. (1977) Historical estimates of world population: an evaluation. Popul. Dev. Rev. 3, 253-296

12 Vermeij, G.J. and Leigh, E.G., Jr (2011) Natural and human economies compared. Ecosphere 2, art39
13 Chatterjee, A. et al., eds (2005) Econophysics of Wealth Distributions, Springer Verlag

14 Hardin, G. (1968) The tragedy of the commons. Science 162, 1243-1248

15 Ostrom, E. et al. (1999) Revisiting the commons: local lessons, global challenges. Science 284, 278-282

0169-5347/\$ - see front matter ๑ 2012 Elsevier Ltd. All rights reserved http://dx.doi.org/10.1016/j.tree.2012.12.001 Trends in Ecology \& Evolution, March 2013, Vol. 28 , No. 3 